\title{
Visits at artificial RFID flowers demonstrate that juvenile flower-visiting bats perform foraging flights apart from their mothers
}

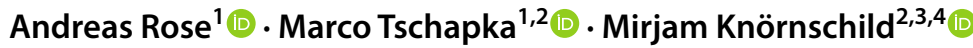

Received: 18 January 2020 / Accepted: 19 June 2020 / Published online: 21 July 2020

(c) The Author(s) 2020

\begin{abstract}
During the transition from parental care to independent life, the development of adequate foraging skills is a major challenge for many juvenile mammals. However, participating in their parents' knowledge by applying social learning strategies might facilitate this task. For several mammals, communal foraging of adults and offspring is suggested to be an important mechanism in mediating foraging-related information. For the large mammalian taxon of bats, only little is known about foragingrelated social learning processes during ontogeny. It is often suggested that following their mothers during foraging flights would represent a valuable option for juveniles to socially learn about foraging, e.g., where to find resource-rich foraging patches, but explicit tests are scarce. In the present study, we investigated the foraging behavior of juvenile flower-visiting bats (Glossophaga soricina) in a dry forest in Costa Rica. We tested whether recently volant, but still nursed pups perform foraging flights alone, or whether pups follow their mothers, which would enable pups to socially learn where to feed. For that, we trained mothers and pups to feed from artificial flowers with a RFID reading system and, subsequently, conducted a field experiment to test whether RFID-tagged mothers and pups visit these flowers communally or independently. Unexpectedly, pups often encountered and visited artificial flowers near the day roost, while mothers rarely did, suggesting that they foraged somewhere further away. Our results demonstrate that still nursed juveniles perform foraging flights apart from their mothers and might learn about the spatial distribution of food without participating in their mother's knowledge, for instance, by following other conspecifics or applying individual learning strategies. An initial potential lack of foraging success in this period is likely compensated by the ongoing maternal provisioning with breast milk and regurgitated nectar during daytime. Our results contribute to the growing body of research on the ontogeny of mammalian foraging behavior in general.
\end{abstract}

Keywords Development of foraging behavior $\cdot$ Chiroptera $\cdot$ Glossophaga soricina $\cdot$ Individual learning $\cdot$ PIT tags

Handling editor: Danilo Russo.

Electronic supplementary material The online version of this article (https://doi.org/10.1007/s42991-020-00048-4) contains supplementary material, which is available to authorized users.

Andreas Rose

andreasroseulm@gmail.com

1 Institute of Evolutionary Ecology and Conservation Genomics, University of Ulm, Albert-Einstein Allee 11, 89069 Ulm, Germany

2 Smithsonian Tropical Research Institute, Building 401 Tupper, Luis Clement Avenue, Balboa, Ancon, Republic of Panama

3 Animal Behavior Lab, Free University Berlin, Takustrasse 6, 14195 Berlin, Germany

4 Museum für Naturkunde-Leibniz Institute for Evolution and Biodiversity Science, Invalidenstraße 43, 10115 Berlin, Germany

\section{Introduction}

Transition from parental care to independent life is a major step in the ontogeny of mammals. During this time, the development of adequate foraging skills might be the most significant challenge, covering learning about "when, where, what and how to eat" (Galef and Giraldeau 2001). However, participating in their parents' knowledge is suggested to facilitate this developmental period in several species (reviewed in Box and Gibson 1999; Galef and Giraldeau 2001). Following behavior and communal foraging of adults and offspring might represent a widespread mechanism in mediating a vertical social transmission of foraging-related information. By accompanying foraging parents, juvenile mammals might socially learn about the distribution of foraging patches (Wilkinson 1992), how to exploit complicated food items (Aisner and Terkel 1992), avoid poisonous food 
(Galef and Clarck 1971), or to improve predatory skills (Kitchener 1999).

For bats, there is only very little knowledge about social learning processes during ontogeny and whether foragingrelated information is socially transmitted from parents to offspring (Wright 2016; Prat and Yovel 2020). Although bats are highly diverse in terms of their feeding habits, ranging from predatory species to those seeking fruits or nectar, inexperienced juveniles of all species face the challenge of properly deciding when, where, what, and how to feed (Galef and Giraldeau 2001; Prat and Yovel 2020). However, experiments on social learning between parents and offspring are scarce (Wright et al. 2011; Ganesh et al. 2016; Ripperger et al. 2019; Rose et al. 2019), and the transmission of social information among adult bats was primarily studied in laboratory experiments with forced spatial proximity between individuals (reviewed in Wilkinson 1995; Wilkinson and Boughman 1999; Wright 2016). Besides using innate knowledge about principles of foraging behavior and individual learning strategies, young bats should have plenty opportunities to gain information from adults. Comparable to other mammals, it was often argued that following their mothers during first foraging flights would represent a suchlike valuable option for juveniles to socially learn about foraging, e.g., where to find resource-rich foraging patches (Brigham and Brigham 1989; Altringham 1996; Wright 2016). However, there are only very few explicit tests on communal or independent foraging of mother-pup pairs (e.g., Ripperger et al. 2019). In some animalivorous and frugivorous species, evidence for one or the other strategy is mainly based on partially anecdotal reports with diverse, but rather vague methods, for example, as concluded from emergence observations at roosts (Kunz and Anthony 1996; O'Shea and Vaughan 1977; Duvergé et al. 2000), reasoned from joint captures of mothers and pups in mist nets (Vaughan 1976), and based on mere visual observations (Bradbury and Emmons 1974; Buchler 1980; Racey and Swift 1985; Vaughan and Vaughan 1987) or on the partially coarse spatial resolution of radio-telemetry (Brown et al. 1983; Wilkinson 1985; Brigham and Brigham 1989; Audet 1990; Gopukumar et al. 2003). Nevertheless, these studies indicate that pups of some species might follow parents on foraging flights (e.g., O'Shea and Vaughan 1977; Vaughan and Vaughan 1987; Gopukumar et al. 2003), while others seem to perform an independent foraging strategy (Buchler 1980; Duvergé et al. 2000).

During ontogeny, juveniles have to acquire knowledge their mothers already possess, and transmission of knowledge should be preferable for mothers to minimize risk for their offspring. Potential social learning mechanisms mediated by communal foraging are diverse: the mere presence of the mother might be beneficial for learning by reducing neophobia and promoting explorative behavior in pups
(Zajonc 1965; Voelkl et al. 2006; Dindo et al. 2009; Ganesh et al. 2016). Through following behavior, pups might be able to learn about secure flight paths and the spatial distribution of resource-rich foraging patches (Wilkinson 1995) or might even be enabled to gain information about actual food cues (Page and Ryan 2006; Wright et al. 2011; O'Mara et al. 2014).

Juvenile flower-visiting bats (Phyllostomidae: Glossophaginae) should profit in particular from following their mothers to feeding sites and inflorescences. While innate knowledge about the scent characteristics of bat-pollinated flowers may facilitate independent recognition of suitable flower types (what to feed) (von Helversen et al. 2000), the spatial distribution of foraging patches and flowers (where to feed) is necessarily subject to learning (Thiele and Winter 2005; Rose et al. 2016). In contrast to insects or fruits, flowers are not removed by feeding and will often refill with nectar throughout the night. Inflorescences of chiropterophilous plants may produce flowers over several weeks (Tschapka and Dressler 2002), thus making socially gained information about the spatial distribution of flowers particularly valuable (Rose et al. 2016).

Pallas' long-tongued bats (Glossophaga soricina, Phyllostomidae: Glossophaginae) are medium-sized bats of ca. $10 \mathrm{~g}$ with a neotropical distribution from Mexico to Argentina (Alvarez et al. 1991). These bats mainly feed on nectar and pollen from chiropterophilous flowers, which are lapped out in hovering flight using their elongated tongues (Tschapka et al. 2015). To meet their high energy requirements, bats visit an enormous number of flowers and feed more than their body weight in nectar each night (von Helversen 1986). Adults forage alone (Lemke 1984) but were also observed to forage in flocks (Kruszynski et al. 2016). Females give birth to single pups, which are performing first flights at an age of about one month. At an age of ca. 1.5 months, pups are proficient in performing hovering flights in front of flowers but are alimented by mothers with breast milk and regurgitated nectar for at least two months (Pink 1996; Rose et al. 2019).

In the present study, we investigated whether recently volant, but still nursed pups accompany mothers on foraging flights, or whether mother-pup pairs forage apart. While communal foraging should enable pups to learn about the location of foraging patches socially, independent foraging would suggest pups to be less dependent on their mother's knowledge, for instance, by seeking social information from other conspecifics or by performing individual learning strategies.

\section{Materials and methods}

\section{General description of the method}

To investigate the foraging behavior of mother-pup pairs, we arranged artificial flowers in the environment of the bats' 
day roost and tested for communal and independent visits of mothers and their pups. Each flower comprised a RFID reading system that allowed us to precisely record number and time point of visits of mothers and their pups, which were both tagged with RFID transponders.

\section{Capturing, captivity period, and tagging of mother- pup pairs}

During two reproductive periods in 2016 and 2017, we caught 18 lactating female $G$. soricina together with their non-volant pups in the national park Santa Rosa, Costa Rica (UTM: 16P 651137 1198498). Mother-pup pairs were caught with a hand net inside their day roost (16 pairs) or with mist nets (Monofilament, Ecotone, Gdynia, Poland) in front of their presumed roost (2 pairs). Bats were identified as G. soricina following the field key by Timm and LaVal (1998). Capturing bats while pups were still non-volant and attached to their mother's teat during capture was a crucial precondition to allow a clear assignment of pairs. Prior to the field experiment, mother-pup pairs were kept in flight cages for a captivity period of $34.7 \pm 10.2$ days $\left(11.7 \mathrm{~m}^{2}\right.$; Hexagon Screen House; Eureka) and fed with a diet based on NektarPlus (mixing ratio 1:5 in tap water; Nekton $\mathrm{GmbH}$, Pforzheim, Germany) offered in cylindrical bird water feeders with a protruding opening. In 2017, we additionally offered a honey in water solution that we partially enriched with bee pollen and milk powder (NAN Confort Digestivo 2, Nestlé).

After pups became volant and later proficient in feeding on the feeders within the flight cage, we removed feeders and familiarized all bats with one of the artificial RFID flowers (Fig. 1a and detailed information below) that we later used in the field experiment. Mothers and pups fed from this new flower type inside the flight cage for at least two nights before they were released to the field experiment.

Bats were tagged with $125 \mathrm{kHz}$ RFID glass tube transponders (E675-313-Uni, I-KEYS RFID-Technik, Berlin, Germany) that we glued to the slightly sheared upper back between the scapulae using a flexible staying skin bond (SAUER-Hautkleber type 50.22, Manfred Sauer GmbH, Lobbach, Germany). Transponders were covered with a black shrinking tube to protect bats in the highly unlikely case of a destroyed glass tube. Including this cover, transponder weight was $0.28 \mathrm{~g}$ and was therefore even for pups less than $5 \%$ of their body weight, which is suggested not to alter maneuverability (Aldridge and Brigham 1988). Bats were observed to perform increased grooming activities only for a short time after being tagged, but transponders seemed not to have any lasting alteration effects on bats' behavior and adhered for at least 1 week before they fell off.
To ensure that all bats were proficient in feeding on our artificial flower inside the flight cage, we logged bat visits for at least one night before the field experiment started with releasing the tagged bats. Mother-pup pairs that had been captured inside their day roost were released at the same location during the afternoon, and mist-netted pairs were released at the place of capture after sunset.

\section{RFID flowers}

In the field experiment, we tested for communal and independent visits at artificial flowers that we arranged around the bats' day roosts. We used custom-made artificial flowers that comprised a photoelectric through-beam sensor and a RFID reading system, which allowed us to precisely record time and number of visits, as well as the identity of each RFID-tagged individual (Fig. 1a). Computational hard- and software of flowers was based on the Arduino platform and consisted of a microcontroller board (2016: Arduino UNO clone; 2017: Arduino Nano clone; ATmega328P), a RFID unit (RDM6300 v. 2.0), a Real-time-clock (2016: DS1307; 2017: DS3231), and a SD-Card reader. Each flower comprised a nectar reservoir, which was filled with sugar water of $17 \%$ sucrose (azúcar refinado, Victoria, LAICA, Costa Rica). Flowers held enough nectar to never get depleted during an experimental night. To reach the nectar, bats had to insert their head into the protruding rectangular flower opening $(3 \times 4 \mathrm{~cm})$. As all outer parts of the flower, this opening was made out of plastic and carried the RFID antenna and the photoelectric through-beam sensor. The flower opening was slightly inclined downward, roughly resembling the bell-shaped flower type of the chiropterophilous Crescentia alata (Porsch 1931) that is common in the study area. We mounted flowers on string lines in heights of $1.2 \mathrm{~m}$ to $1.9 \mathrm{~m}$ above ground, which were in similar heights as many flowers of two abundant chiropterophilous plants (Crescentia alata and Bauhinia ungulata). However, there are also other plant species occurring in the area that produce flowers much higher above ground (e.g., Pachira quinata).

\section{Experimental setups}

In 2016 (setup "Casona 2016"), our RFID flowers were arranged at a $G$. soricina day roost located inside a room of the historical hacienda "La Casona" in Santa Rosa National Park. This roost was used by a variable number of ca. 20 to 25 individuals. We caught seven mother-pup pairs, of which five pairs were caught with a hand net inside, while two were mist netted in front of the roost. While keeping these bats in a flight cage, mother-pup 

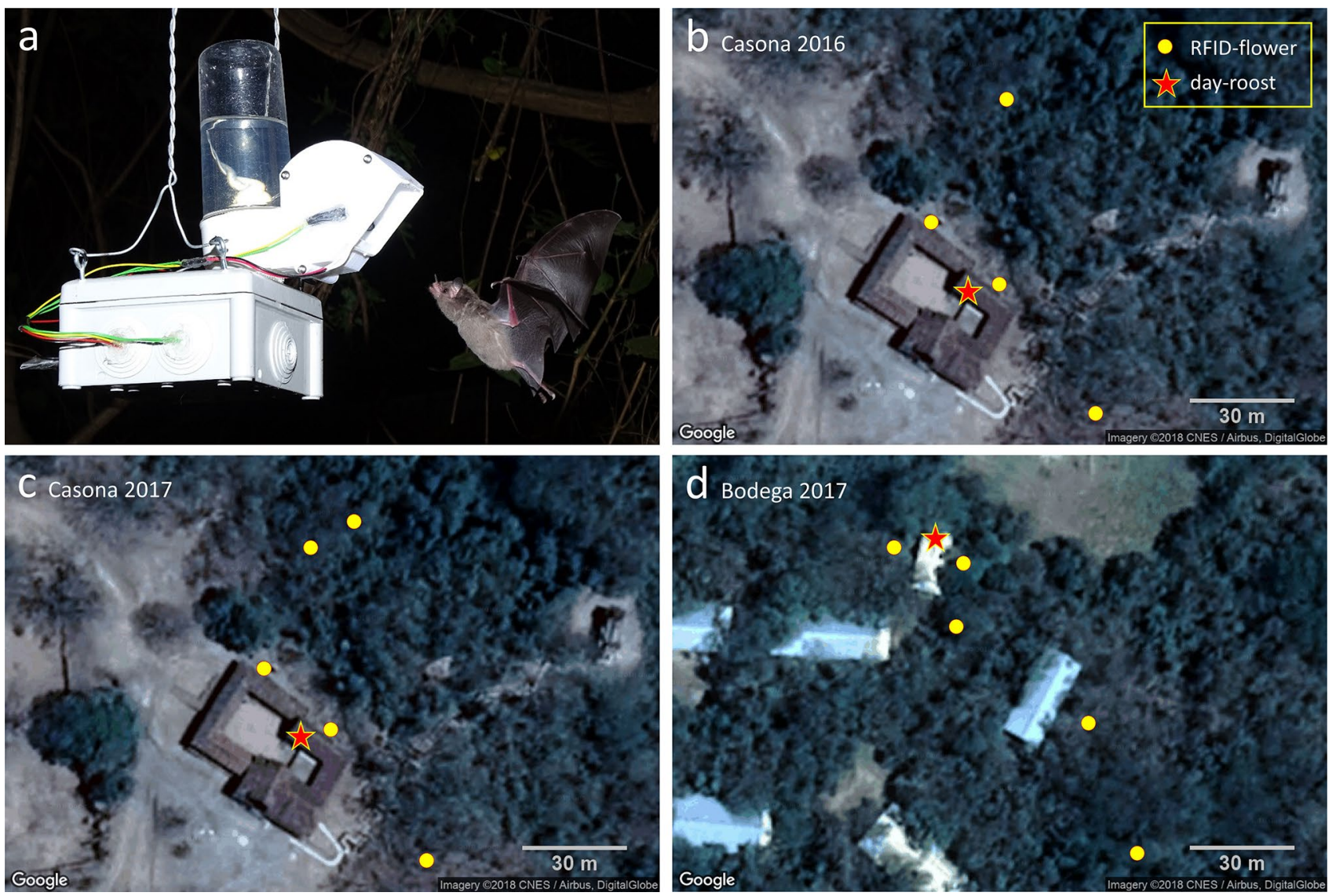

Fig. 1 Artificial RFID flowers (a) were arranged around the day roosts of mother-pup pairs (b-d). In the setups "Casona 2017" (c) and "Bodega 2017" (d), we arranged additional RFID flowers further

away from the roost that are not visible in the displayed map sections (maps modified from Google Maps; Imagery @2018 CNES / Airbus, DigitalGlobe)

pairs were additionally used for an experiment on maternal mouth-to-mouth feeding behavior (Rose et al. 2019). Following this captivity period, all seven mother-pup pairs were released to the field experiment on 25.02.2016. However, from these pairs, we had to exclude two from the further analysis, as their pups were found dead two days after release, one trapped in a cleaning bucket in front of the day roost and the second one on the floor inside. We placed four RFID flowers in the close environment outside the roost (5-60 $\mathrm{m}$ distance): Two were located close to the exterior wall of the historical hacienda, and the other two RFID flowers were mounted in the surrounding forest (Fig. 1b). RFID flowers were active during three consecutive nights, but one flower was not logging visits during the first night due to a technical problem.

In 2017 (setup "Casona 2017"), we caught ten mother-pup pairs from the same day roost as in 2016. All pairs were caught with hand nets inside the roost. Following the captivity period, seven pairs were released on 05.02.2017 and three pairs on 11.02.2017. RFID flowers were arranged at the same locations as in 2016, but we added one additional

flower in the forest near the roost, and four additional RFID flowers at places further away (380-874 m distance): two were mounted at bat-pollinated Crescentia alata trees, one close to a flowering bat-pollinated Bauhinia ungulata, and one was placed at the location of the flight cage where bats were temporarily kept during the captivity period (Fig. 1c). Flowers were active from 05.02.2017 until 17.02.2017. Two flowers were first mounted on 06.02.2017. On 12.02.2017, the nectar reservoir of one flower was hanging down in the morning and was probably not available to the bats for most of this night.

One additional mother-pup pair was caught in 2017 within another day roost, a storeroom of the research station in the park (setup "Bodega 2017"). The pair was released on 23.02.2017. In this setup, we arranged four RFID flowers close to the roost (9-65 $\mathrm{m}$ ) and four further away (105-244 m) (Fig. 1d). Three of the RFID flowers were mounted at the same positions as previously used in the "Casona 2017" setup. Flowers were active from 22.02.2017 until 13.03.2017. 
In total all three experimental setups in 2016 and 2017 provided 34 observation nights with a mean number of $7.9 \pm 1.4$ active RFID flowers, summing up to a total number of 3197.8 RFID flower hours. Overall, we analyzed the behavior of 16 mother-pup pairs with $4.0 \pm 3.6$ pairs per observation night.

\section{Other RFID-tagged bats}

To gain additional data on the foraging behavior and RFID flower usage of unrelated G. soricina and for checking proper function of our setup, we additionally RFID tagged 25 other individuals. In the experimental setup "Casona 2016", we additionally tagged three adult males that were released together with the mother-pup pairs and that were equally familiarized with the RFID flowers before. In the "Bodega 2017" setup, we additionally tagged 22 individuals (10 adult males, 7 adult females, and 5 juveniles/subadults). One adult male was caught together with the mother-pup pair in their day roost and treated equally. The other individuals inhabited unknown day roosts and were mist netted in different nights at varying locations in vicinity to RFID flower positions. Six individuals were familiarized over two nights with the RFID flowers in flight cages before release, while 15 individuals were released immediately after being equipped with transponders.

\section{Statistical analysis of independent or communal foraging of mothers and pups}

For all tagged bats, we analyzed the time, location, and number of visits at our RFID flowers. We excluded RFID reads without associated photoelectric sensor events, as they represented unsuccessful approaches without entering the flower opening, or derived from bats using flowers as temporary perches. A new visit was counted after a pause of at least one second without any sensor event. Visits of mothers and their pups were classified as communal if visits were performed at the same RFID flower position with less than $60 \mathrm{~s}$ interval (either mother or pup visiting the flower first). Otherwise, visits were classified as independent. In case pups discovered a RFID flower position independently from their mother, we additionally analyzed all first encounters to check whether they may have followed unrelated conspecifics.

Photoelectric sensor events without RFID reads were counted as visits of untagged bats. However, this category was of limited reliability since sensors were occasionally also triggered by insects like ants or might have partially derived from tagged bats in case of a failed RFID transmission to the flower. As a consequence, we excluded events after sunrise as well as events of less than $0.1 \mathrm{~s}$ duration, as they were most likely not representing feeding bats.
Statistical analysis was performed in R (v. 3.4.3, R Core Team 2017) using the Rcmdr package by Fox and BouchetValat (2017). Differences in the number of RFID flower visits between mothers and pups were tested using non-parametric Wilcoxon rank-sum test. Numbers of independent and communal visits of mother-pup pairs were compared pairwise by Wilcoxon signed rank test. All tests were performed two sided. Data from both years were pooled for analyses. If multiple tests were performed on the same dataset, we adjusted significance level $(\alpha=0.05)$ using sequential Bonferroni correction. Maps for spatial visualization of RFID flower positions were created using the get_map function in the ggmap package by Kahle and Wickham (2013).

\section{Observations on pup development during the captivity period}

Pup growth was documented by taking measurements of each individual at least at the day of capture and before releasing them to the field experiment. We measured length of forearm (FA) with a caliper to the nearest $0.1 \mathrm{~mm}$ and body mass (BM) with a spring balance to the nearest $0.5 \mathrm{~g}$. Identification of individuals and assignment of pairs were realized by marking mothers with color-coded collars and by shearing small parts of the fur at identical locations in mothers and pups or by perforating wing membranes at same locations with a small biopsy punch ( $2 \mathrm{~mm}$ ). In 2017, nursing behavior of mother-pup pairs during daytime was documented at least on the day before bats were released to the field experiment with a camcorder or by taking photographs.

\section{Results}

\section{Development and behavior prior to the field experiment}

At the day of capture, all pups were non-volant with BM of $4.8 \pm 1.1 \mathrm{~g}$ (mean \pm standard deviation) and a FA of $26.7 \pm 4.3 \mathrm{~mm}$. When pairs were released into the field experiment after $34.7 \pm 10.2$ days of captivity, pups were proficient in flying and in performing hovering flights while feeding from the RFID flower. At that time, body measurements of pups had increased to a BM of $7.7 \pm 1.1 \mathrm{~g}$ and FA of $34.9 \pm 0.7 \mathrm{~mm}$ but had not yet reached body measurements of mothers (BM: $10.8 \pm 0.7 \mathrm{~g}, \mathrm{FA}: 35.8 \pm 1.1 \mathrm{~mm}$ ). Finger joints were still not ossified, indicating that bones were not yet fully grown (Brunet-Rossinni and Wilkinson 2009). When pairs were released for the field experiment, pups were still not weaned and clinging during the day for long periods on their mother while being nursed with breast milk. In their last night in the flight cage, pups performed each a mean of $101.8 \pm 59.7$ visits on the RFID flower, while 
the number of visits by mothers was considerably higher $[226.6 \pm 80.0$, Wilcoxon rank-sum test: $W=293, p<0.001$ $(\alpha=0.05)]$.

\section{Foraging behavior of mother-pup pairs in the field experiment}

In the field experiment, we found distinct differences in the foraging behavior of mothers and pups. While pups often visited RFID flowers in the vicinity to their roost, visits of mothers were hardly recorded [RFID flower visits: pups $(n=16): 233.9 \pm 263.9$ (median: 94.5$)$; mothers $(n=16)$ : $1.1 \pm 4.4$ (median: 0.0), Wilcoxon rank-sum test with continuity correction: $W=53, p<0.001(\alpha=0.025)]$. RFID flower visits were performed independently and we did not register any communal RFID flower visit of mother-pup pairs $(n=16$ pairs, independent visits: $235.0 \pm 264.5$ (median: 94.5; total: 3760 ), communal visits: $0 \pm 0$; Wilcoxon signed rank test with continuity correction, $V=55$, $p<0.01(\alpha=0.05)$. While ten pups encountered at least one of the RFID flowers and performed in total 3742 visits, only one mother fed from a RFID flower (Table 1). Her visits were not temporarily associated to visits of her pup, which had fed at the same position for the last time 9 min earlier.

Pups also differed in their success of encountering RFID flower positions. While some pups were never logged visiting RFID flowers $(n=6=37.5 \%)$, others were able to encounter up to five RFID flower positions in distances of up to $60 \mathrm{~m}$ from their roost (Table 1). In only four of 23 first encounters of a RFID flower position, a conspecific other than the mother had fed from the particular flower in the previous minute (another RFID-tagged pup: 3 , untagged bat: 1), suggesting that pups discovered flowers predominantly alone.

\section{Other RFID-tagged bats}

In all three setups of the field experiment, RFID flowers were also visited by other bats. Although none of the three additionally tagged adult males in the experimental setup "Casona 2016" visited a RFID flower, we were able to record 300 visits of untagged bats. In "Casona 2017" we counted 1154 visits of untagged bats and in "Bodega 2017" we recorded 32,145 visits of untagged bats as well as 1708 visits from five of the additionally tagged individuals (Supplementary tables S1, S2, S3).

\section{Discussion}

Our finding that none of the 3742 visits of pups at RFID flowers were temporarily associated with a visit of the respective mother demonstrates that juvenile G. soricina perform foraging flights independently from their mothers. The results may further indicate different search strategies and foraging areas of mothers and their pups. While most pups found the RFID flowers in close vicinity to the roost, this was achieved by only one of the mothers. We have no

Table 1 In the field experiment, pups were more likely than mothers to encounter and visit RFID flower positions around their day roost, and we did not record any communal RFID flower visits of mother-pup pairs

\begin{tabular}{|c|c|c|c|c|c|c|}
\hline ID & $\begin{array}{l}\text { Visits by } \\
\text { mother }\end{array}$ & $\begin{array}{l}\text { RFID flowers encoun- } \\
\text { tered by mother }\end{array}$ & Visits by pup & $\begin{array}{l}\text { RFID flowers encoun- } \\
\text { tered by pup }\end{array}$ & $\begin{array}{l}\text { Communal } \\
\text { visits }\end{array}$ & Experimental setup \\
\hline pair_428/4C3 & 0 & 0 & 353 & 2 & 0 & "Casona 2016" \\
\hline pair_4AC/EBA & 0 & 0 & 0 & 0 & 0 & "Casona 2016" \\
\hline pair_834/7E5 & 0 & 0 & 421 & 3 & 0 & "Casona 2016" \\
\hline pair_9C0/337 & 18 & 1 & 353 & 4 & 0 & "Casona 2016" \\
\hline pair_F89/777 & 0 & 0 & 0 & 0 & 0 & "Casona 2016" \\
\hline pair_072/49D & 0 & 0 & 745 & 5 & 0 & "Casona 2017" \\
\hline pair_56E/009 & 0 & 0 & 8 & 1 & 0 & "Casona 2017" \\
\hline pair_573/8D6 & 0 & 0 & 0 & 0 & 0 & "Casona 2017" \\
\hline pair_7C0/2C7 & 0 & 0 & 12 & 1 & 0 & "Casona 2017" \\
\hline pair_80E/3FF & 0 & 0 & 561 & 3 & 0 & "Casona 2017" \\
\hline pair_94C/CC1 & 0 & 0 & 0 & 0 & 0 & "Casona 2017" \\
\hline pair_C84/8E2 & 0 & 0 & 408 & 2 & 0 & “Casona 2017" \\
\hline pair_683/385 & 0 & 0 & 0 & 0 & 0 & "Casona 2017" \\
\hline pair_F0E/DA7 & 0 & 0 & 177 & 1 & 0 & "Casona 2017" \\
\hline pair_93E/FA1 & 0 & 0 & 0 & 0 & 0 & "Casona 2017" \\
\hline pair_2F1/A56 & 0 & 0 & 704 & 1 & 0 & "Bodega 2017" \\
\hline
\end{tabular}


doubt that mothers would have readily fed on the offered RFID flowers in case of encountering them. These flowers represented a familiar and unlimited source of energy: mothers were used to feed on this flower type and had visited it already hundreds of times in the flight cage, and the sugar concentration of $17 \%$ was in the upper range of real bat-pollinated flowers (von Helversen 1995). Visits of additionally tagged and untagged individuals further demonstrate the generally good acceptance by wild bats. We suggest that the observed differences in the success of encountering the RFID flowers in vicinity to the roost were caused by different search strategies of mothers and pups, and might be explained with different levels of knowledge. After bats were released to the field experiment, mothers were instantly able to use their excellent spatial memory to draw on their former knowledge about valuable foraging patches and the respective flight paths (Thiele and Winter 2005; Rose et al. 2016). Thus, when emerging from the day roost after sunset, they probably flew directly to their common and established foraging grounds in their large home ranges of several hundred hectares (Aguiar et al. 2014), without spending energy on search flights near the roost. However, due to their lower body mass, pups might lack the crucial energy reserves to follow mothers to faroff foraging places. Pups further start without any spatial information when emerging from the day roost for the first time and, if they do not accompany their mothers, have to rely on their innate knowledge about principal characteristics of bat-pollinated flowers (von Helversen et al. 2000), and, in our study, additionally on the artificially added knowledge about the shape of our RFID flowers. By lacking any spatial information about the vicinity and about the distribution of resource-rich foraging patches, independently foraging pups had to progressively explore the environment to get familiar with the outside terrain and were thus more likely than mothers to encounter our RFID flowers.

Performing flights close to the roost was observed for pups of animalivorous bats by Racey and Swift (1985), who documented that juveniles of the common pipistrelle (Pipistrellus pipistrellus) foraged progressively further away from their roost over a three-week period, and by Buchler (1980), who reported that young little brown bats (Myotis lucifugus) stayed within an area of 50-75 m to the roost. Likewise, Adams (1997) documented a foraging area segregation between age classes in Myotis lucifugus and Dwyer (1963) reported that early foraging flights of juvenile common bent-wing bats (Miniopterus schreibersii) were significantly shorter than flights of adults.

Previous studies used various approaches to investigate foraging strategies of juvenile bats, ranging from mere visual observations to proximity sensor systems. Although the evidence for either communal or independent foraging strategies of mother-pup pairs remains in most reports largely anecdotal, pups of some animalivorous species are likely foraging independent from their mother (Buchler 1980; Racey and Swift 1985; Audet 1990; Kunz and Anthony 1996; Hamilton and Barclay 1998; Duvergé et al. 2000; Rippberger et al. 2019), while in some other animalivorous and frugivorous species, mother-pup pairs seem to perform a communal foraging strategy (Bradbury and Emmons 1974; Vaughan 1976; Brown et al. 1983; Wilkinson 1985; Vaughan and Vaughan 1987; Brigham and Brigham 1989; Gopukumar et al. 2003). However, this picture is patchy and there is still no clear pattern which factors might promote one or the other strategy in different species. While communal mother-pup foraging was primarily discussed with regard to transmission of social information about foraging (Vaughan and Vaughan 1987; Wilkinson 1992; Gopukumar et al. 2003), independent foraging was discussed to be beneficial to avoid predators (Kunz and Anthony 1996) or caused by avoiding confusion by echolocation pulses of conspecifics during auditory ontogeny (Buchler 1980; Kunz and Anthony 1996). However, an avoidance of acoustic clutter might be an unlikely reason for solitary foraging in whispering bats, such as $G$. soricina, as these bats emit echolocation calls with strong directionality (Howell 1974).

Although independent foraging of mother-pup pairs may indicate that pups are not participating in their mother's knowledge for increasing their informational repertoire about flower positions, conclusions about the necessity of social learning processes during ontogeny have to be drawn carefully. For example, as bats roost in groups, following behavior may not be limited to the own mother (Wilkinson 1995), or pups might first switch to a social learning strategy after remaining unsuccessful alone. In our experiment, the latter strategy may have been altered due to presenting RFID flowers in relatively close distance to their day roost. Further, pups already learned about the RFID flower type before starting the field experiment. Thus, while searching for positions of already known flower types might be possible alone, the presence of the mother or any other more experienced bat could be crucial for pups when learning about a novel flower type.

However, individual learning strategies are conceivable for flower bats, since a potential initial lack of foraging success could be compensated by the ongoing maternal provisioning. Glossophaga soricina pups are not weaned until an age of two months (Pink 1996; personal observations), and if pups are not successful with foraging for one night, they can still rely on breast milk after being reunited with their mother during the day. This required daily reunion of independently foraging mother-pup pairs is ensured by the bats' habit to faithfully use the same day roost (personal observations). In contrast to roaming animals 
without such daily meeting points, bat pups might not face a high risk after a temporal separation from their mother. In addition to breast-feeding during the day, unsuccessful pups might be visited by mothers even throughout the night and provisioned with regurgitated floral nectar via mouth-to-mouth feeding behavior (Rose et al. 2019). Such a temporal overlap of parental provisioning and first foraging experiences of juveniles seems to be common to compensate initial foraging deficiencies and maintain a gentle transition from parental care to independent life. For example, pups of greater false vampire bats (Megaderma lyra) are still nursed when they are already foraging on their own (Raghuram and Marimuthu 2007), young of common big-eared bats (Micronycteris microtis) are provisioned even post-weaning by mothers (Geipel et al. 2013), while common vampire bats (Desmodus rotundus) perform even a lifelong food sharing with unsuccessful roost-mates (Wilkinson 1984). In general, the length of this parental provisioning and the temporal overlap from first foraging attempts of pups until complete independence might provide fruitful insights about the associated individual or social learning challenge for pups until they become proficient foragers.

For G. soricina and bats in general, knowledge about individually and socially learned components in the juvenile development of foraging behavior remains scarce. It is very likely that the high ecological diversity of bats may have led to different behavioral adaptations to facilitate a soft transition from maternal care to independent life. In the future, technically advanced systems with lightweight proximity sensors might represent a valuable option to test respective hypotheses (Ripperger et al. 2020).

Acknowledgements We are grateful to the Costa Rican authorities for allocating research permits (ACG-PI-059-2015 and ACGPI-055-2016). We thank Roger Blanco and all the other people from the Área de Conservación Guanacaste (ACG) and the Parque Nacional Santa Rosa for excellent logistic support and providing infrastructure for fieldwork.

Funding Open access funding provided by Projekt DEAL. This work was funded by a stipend from the Rosa Luxemburg Foundation to AR and a Heisenberg Fellowship of the Deutsche Forschungsgemeinschaft (DFG; German Research Foundation) to MK (DFG KN935 3-1).

Data availability The dataset collected and analyzed during the current study is available from the corresponding author on reasonable request.

\section{Compliance with ethical standards}

Conflict of interest The authors declare that they have no conflict of interest.

Ethical approval All applicable international, national, and institutional guidelines for the care and use of animals were followed. Handling of animals was reduced to the necessary minimum and handling was always performed with respect to the avoidance of stress. Permissions for the work in Costa Rica were granted by the Costa Rican government (permit numbers: ACG-PI-059-2015 and ACG-PI-055-2016).

Open Access This article is licensed under a Creative Commons Attribution 4.0 International License, which permits use, sharing, adaptation, distribution and reproduction in any medium or format, as long as you give appropriate credit to the original author(s) and the source, provide a link to the Creative Commons licence, and indicate if changes were made. The images or other third party material in this article are included in the article's Creative Commons licence, unless indicated otherwise in a credit line to the material. If material is not included in the article's Creative Commons licence and your intended use is not permitted by statutory regulation or exceeds the permitted use, you will need to obtain permission directly from the copyright holder. To view a copy of this licence, visit http://creativecommons.org/licenses/by/4.0/.

\section{References}

Adams RA (1997) Onset of volancy and foraging patterns of juvenile little brown bats, Myotis lucifugus. J Mammal 78:239-246

Aguiar LMS, Bernard E, Machado RB (2014) Habitat use and movements of Glossophaga soricina and Lonchophylla dekeyseri (Chiroptera: Phyllostomidae) in a Neotropical savannah. Zool 31:223-229

Aisner R, Terkel J (1992) Ontogeny of pine cone opening behaviour in the black rat, Rattus rattus. Anim Behav 44:327-336

Aldridge HDJN, Brigham RM (1988) Load carrying and maneuverability in an insectivorous bat: a test of the 5\% "rule" of radiotelemetry. J Mammal 69:379

Altringham JD (1996) Bats biology and behaviour. Oxford University Press, New York

Alvarez J, Willing M, Jones K, Webster D (1991) Glossophaga soricina. Mamm Species 379:1-7

Audet D (1990) Foraging behavior and habitat use by a gleaning bat, Myotis myotis (Chiroptera: Vespertilionidae). J Mammal 71:420-427

Box HO, Gibson KR (eds) (1999) Mammalian social learning: comparative and ecological perspectives. Cambridge University Press, Cambridge

Bradbury JW, Emmons LH (1974) Social Organization of some Trinidad Bats: I. Emballonuridae Z Tierpsychol 36:137-183

Brigham RM, Brigham C (1989) Evidence for association between a mother bat and its young during and after foraging. Am Midl Nat 121:205-207

Brown PE, Brown TW, Grinnell AD (1983) Echolocation, development, and vocal communication in the lesser bulldog bat, Noctilio albiventris. Behav Ecol Sociobiol 13:287-298

Brunet-Rossinni A, Wilkinson G (2009) Methods for age estimation and the study of senescence in bats. In: Kunz T, Parsons S (eds) Ecological and behavioral methods for the study of bats. Johns Hopkins University Press, Baltimore, pp 315-326

Buchler ER (1980) The development of flight, foraging, and echolocation in the little brown bat (Myotis lucifugus). Behav Ecol Sociobiol 6:211-218

Dindo M, Whiten A, de Waal FBM (2009) Social facilitation of exploratory foraging behavior in capuchin monkeys (Cebus apella). Am J Primatol 71:419-426

Duvergé PL, Jones G, Rydell J, Ransome RD (2000) Functional significance of emergence timing in bats. Ecography (Cop) 23:32-40

Dwyer PDDA-1963 (1963) The breeding biology of Miniopterus schreibersii blepotis (Temminck) (Chiroptera) in north-eastern New South Wales. Aust J Zool 11:219-240 
Fox J, Bouchet-Valat M (2017) Rcmdr: R Commander. R package version 2.4-1

Galef BG, Clark MM (1971) Social factors in the poison avoidance and feeding behavior of wild and domesticated rat pups. J Comp Physiol Psychol 75:341-357

Galef BG, Giraldeau L-A (2001) Social influences on foraging in vertebrates: causal mechanisms and adaptive functions. Anim Behav 61:3-15

Ganesh A, Mukilan M, Marimuthu G, Rajan KE (2016) A novel food preference in the greater short-nosed fruit bat, Cynopterus sphinx: Mother-pup interaction a strategy for learning. Acta Chiropterologica 18:193-198

Geipel I, Kalko EKV, Wallmeyer K, Knörnschild M (2013) Postweaning maternal food provisioning in a bat with a complex hunting strategy. Anim Behav 85:1435-1441

Gopukumar N, Nathan PT, Doss PS et al (2003) Early ontogeny of foraging behaviour in the short-nosed fruit bat Cynopterus sphinx (Megachiroptera): preliminary results. Mammalia 67:139-145

Hamilton IM, Barclay RMR (1998) Diets of juvenile, yearling, and adult big brown bats (Eptesicus fuscus) in southeastern Alberta. J Mammal 79:764-771

Howell D (1974) Acoustic behavior and feeding in glossophagine bats. J Mammal 55:293-308

Kahle D, Wickham H (2013) ggmap: spatial visualization with ggplot2. R J 5(1):144-161

Kitchener AC (1999) Watch with mother: a review of social learning in the Felidae. Mammalian social learning: comparative and ecological perspectives. University of Texas, Houston, pp 80-101

Kruszynski C, Diniz-Reis TR, Pedrozo AR (2016) A new food resource for Glossophaga soricina (Mammalia: Chiroptera) in southeast Brazil. Bol Soc Bras Mastozool 77:124-130

Kunz TH, Anthony ELP (1996) Variation in the timing of nightly emergence behaviour in the little brown bat, Myotis lucifugus (Chiroptera: Vespertilionidae). Texas Tech University Press, Lubbock, pp 225-235

Lemke TO (1984) Foraging ecology of the long-nosed bat, Glossophaga soricina, with respect to resource availability. Ecology 65:538-548

O'Mara MT, Dechmann DKN, Page RA (2014) Frugivorous bats evaluate the quality of social information when choosing novel foods. Behav Ecol 25:1233-1239

O'Shea TJ, Vaughan TA (1977) Nocturnal and seasonal activities of the pallid bat, Antrozous pallidus. J Mammal 58:269-284

Page R, Ryan MJ (2006) Social transmission of novel foraging behavior in bats: frog calls and their referents. Curr Biol 16:1201-1205

Pink B (1996) Fortpflanzungs- und Sozialverhalten der blütenbesuchenden Fledermausart Glossophaga soricina (Phyllostomidae; Glossophaginae). Diploma Thesis. University of Erlangen-Nuremberg.

Porsch O (1931) Crescentia-eine Fledermausblume. Österreichische Botanische Zeitschrift 80:31-44

Prat Y, Yovel Y (2020) Decision making in foraging bats. Curr Opin Neurobiol 60:169-175

R Core Team (2017) R: a language and environment for statistical computing. R Foundation for Statistical Computing, Vienna, Austria. https://www.R-project.org/.

Racey PA, Swift SM (1985) Feeding ecology of Pipistrellus pipistrellus (Chiroptera: Vespertilionidae) during pregnancy and lactation. I. Foraging behaviour. J Anim Ecol 54:205-215

Raghuram H, Marimuthu G (2007) Maternal feeding of offspring with vertebrate prey in captive Indian false vampire bat, Megaderma lyra. Acta Chiropterologica 9:437-443

Ripperger S, Günther L, Wieser H, Duda N, Hierold M, Cassens B, Kapitza R, Koelpin A, Mayer F (2019) Proximity sensors on common noctule bats reveal evidence that mothers guide juveniles to roosts but not food. Biol Lett 15:20180884
Ripperger SP, Carter GG, Page RA, Duda N, Koelpin A, Weigel R, Hartmann M, Nowak T, Thielecke J, Schadhauser M, Robert J, Herbst S, Meyer-Wegener K, Wägemann P, Schröder-Preikschat W, Cassens B, Kapitza R, Dressler F, Mayer F (2020) Thinking small: nextgeneration sensor networks close the size gap in vertebrate biologging. PLoS Biol 18(4):e3000655

Rose A, Kolar M, Tschapka M, Knörnschild M (2016) Learning where to feed: the use of social information in flower-visiting Pallas' longtongued bats (Glossophaga soricina). Anim Cogn 19:251-262

Rose A, Wöhl S, Bechler J, Tschapka M, Knörnschild M (2019) Maternal mouth-to-mouth feeding behaviour in flower-visiting bats, but no experimental evidence for transmitted dietary preferences. Behav Proc 165:29-35

Thiele J, Winter Y (2005) Hierarchical strategy for relocating food targets in flower bats: spatial memory versus cue-directed search. Anim Behav 69:315-327

Timm RM, LaVal RK (1998) A Field Key to the Bats of Costa Rica. Occas Publ Ser Cent Lat Am Stud 22:1-30

Tschapka M, Dressler S (2002) Chiropterophily: On bat-flowers and flower-bats. Curtis's Bot Mag 19:114-125

Tschapka M, Gonzalez-Terrazas TP, Knörnschild M (2015) Nectar uptake in bats using a pumping-tongue mechanism. Sci Adv 1:e1500525-e1500525

Vaughan TA (1976) Nocturnal behavior of the African false Vampire bat (Cardioderma cor). J Mammal 57:227-248

Vaughan TA, Vaughan RP (1987) Parental behavior in the African yellow-winged bats (Lavia frons). J Mammal 68:217-223

Voelkl B, Schrauf C, Huber L (2006) Social contact influences the response of infant marmosets towards novel food. Anim Behav $72: 365-372$

von Helversen O (1986) Blütenbesuch bei Blumenfledermäusen: Kinematik des Schwirrfluges und Energiebudget im Freiland. Biona-Rep 5:107-126

von Helversen O (1995) Blumenfledermäuse und FledermausblumenWechselbeziehungen zwischen Blüte und Bestäuber und energetische Grenzbedingungen. Rundgespräche der Kommission für Ökologie 10:217-229

von Helversen O, Winkler L, Bestmann HJ (2000) Sulphur-containing "perfumes" attract flower-visiting bats. J Comp Physiol A Neuroethol Sens Neural Behav Physiol 186:143-153

Wilkinson GS (1984) Reciprocal food sharing in the vampire bat. Nature 308:181-184

Wilkinson GS (1985) The social organization of the common vampire bat I. Pattern and cause of association. Behav Ecol Sociobiol 17:111-121

Wilkinson G (1992) Information transfer at evening bat colonies. Anim Behav 44:501-518

Wilkinson GS (1995) Information transfer in bats. Symp Zool Soc London 67:345-360

Wilkinson G, Boughman J (1999) Social influences on foraging in bats. Mammalian social learning: comparative and ecological perspectives. Cambridge University Press, Cambridge, pp 189-204

Wright GS (2016) Social learning and information transfer in bats: conspecific influence regarding roosts, calls, and food. Sociality in Bats. Springer International Publishing, Berlin, pp 211-230

Wright GS, Wilkinson GS, Moss CF (2011) Social learning of a novel foraging task by big brown bats, Eptesicus fuscus. Anim Behav 82:1075-1083

Zajonc R (1965) Social facilitation. Science 149:269-274

Publisher's Note Springer Nature remains neutral with regard to jurisdictional claims in published maps and institutional affiliations. 